\title{
O Desafio da Integração Social no Mercosul
}

\author{
Bouzid |zerrougene $e^{(*)}$
}

Resumo: $\mathrm{O}$ artigo discute a possibilidade de garantir direitos sociais fundamentais à população do Mercosul, consideradas tanto a lógica comercial do bloco e as dificuldades orçamentárias das economias da região, quanto as diversidades nas realidades sociais, econômicas e jurídicas dos países sócios.

Palavras-chave: Direitos Sociais, Mercosul, Equidade, Divergências, Integração.

\begin{abstract}
This paper discusses the possibility to guarantee the fundamental social rights of the Mercosul's population. It considers the Mercosul's commercial logic, the budgetary difficulties and the social, economics and juridical divergences among the partner countries.
\end{abstract}

Keywords: Social Rights, Mercosul, Equity, Divergencies, Integration.

(*) Doutor em Economia pela universidade Paris-Villetaneuse, Professor no Curso de Mestrado de Economia da Ufba. E-mail: bouzid@ufba.br. Recebido em: 16.10.08 e aceito em: 2.12.08.

100 


\section{INTRODUÇÃo}

Sabe-se que a integração regional do Mercosul (MS) obedece a uma lógica predominantemente comercial e nela prevalece a regra do consenso intergovernamental. Contudo, a dimensão social da integração e o fortalecimento institucional do bloco são preocupações fundamentais que se impõem cada vez mais nas agendas de negociação. A unificação das políticas sociais e, de modo mais ambicioso, a criação de uma cidadania social comunitária (apoiada em direitos e sistemas comuns de proteção social básica a todos os cidadãos da região) têm sido crescentemente propostas como metas do MS social.

Como será possível então unir esforços para efetivar o acesso universal e equânime a direitos humanos básicos como os da saúde, moradia, educação, segurança e emprego, considerados problemas como as dificuldades orçamentárias, a pobreza e o envelhecimento das populações, os desequilíbrios dos sistemas nacionais de seguridade e as diversidades nas realidades econômicas e jurídicas nos países parceiros? Quais serão os possíveis efeitos da integração sobre os benefícios sociais nos países do MS? Tais são as preocupações que envolvem as discussões sobre a questão social no MS e cuja abordagem implica necessariamente intervenção pública.

\section{A NeCESSidade de políticas Sociais}

A exclusão social é marcante nos países do MS, como é o caso de toda a América Latina $^{(1)}$. Com uma população de cerca de 300 milhões de habitantes no MS ampliado ${ }^{(2)}$, mais de um terço não está coberto por mecanismos de proteção social; mais de 70 milhões de pessoas não têm acesso aos serviços de saúde, e nem mesmo à água potável ou saneamento básico; e, grande parte da população das grandes cidades se depara diariamente com a violência urbana. Os esforços para assegurar direitos sociais mínimos se esbarram com um padrão de forte iniquidade, resultante de desequilíbrios acumulados ao longo de séculos e que transformaram a região numa área de extrema concentração de renda e flagrantes desequilíbrios sociais e territoriais.

No Brasil e no Paraguai, as causas da pobreza extrema são antes de caráter estrutural e histórico, sendo o reflexo da grande concentração da riqueza nessas sociedades, daí a importância de medidas emergenciais de assistência pública. No Paraguai, os 20\% da população constituída pelos mais ricos detêm cerca de $60 \%$ do PIB, enquanto que os $20 \%$ mais pobres têm apenas $3 \%$ do rendimento nacional ${ }^{(3)}$. No Brasil, onde se observa a segunda pior distribuição de renda do mundo de acordo com o índice de Gini ${ }^{(4)}$, a concentração das riquezas nos últimos 20 anos aumentou. Os ricos representam apenas $2 \%$ da população e ganham acima de 20 salários mínimos. Em 2002, os 20\% mais pobres tiveram acesso a

(1) O número de pobres na América Latina saltou de 136 milhões em 1980, para 214 milhões em 2001. Quase 43\% da população latino-americana vivem na pobreza. $18,6 \%$ são indigentes. Dados da Cepal, Panorama Social da América Latina, 2004 .

(2) Argentina, Brasil, Bolívia, Chile, Paraguai, Uruguai e Venezuela.

(3) Dados da UNDP, Relatório do Desenvolvimento Humano 2007/2008. Nações Unidas.

(4) O índice do Brasil é de 0,60, sendo superado só por Serra Leoa $(0,62)$. 
$4,2 \%$ do rendimento nacional, enquanto que os $20 \%$ mais ricos detinham $56,8 \%$ do $\operatorname{PIB}^{(5)}$. Além disso, registram-se diferenças regionais significativas. A participação dos $20 \%$ mais ricos era de $54 \%$ no sudeste e $63 \%$ no nordeste brasileiros ${ }^{(6)}$. Na Argentina, nos últimos 30 anos, uma faixa de $10 \%$ da população, referente aos mais pobres, reduziu sua renda em $54,8 \%$, e os mais ricos a aumentaram em $58,9 \%{ }^{(7)}$. Neste país, como no Uruguai, o agravamento da pobreza está em grande parte ligado às recentes alterações do mercado de trabalho. Concretamente, na Argentina, a taxa de pobreza durante a crise econômica aumentou de $32,8 \%$ em 2000 para mais de $50 \%$ em $2002^{(8)}$. A diminuição da pobreza neste país depende diretamente do dinamismo da atividade econômica, da melhoria do emprego regular e da relação capital-trabalho.

Embora os programas destinados à redução da pobreza e da indigência tenham prosseguido durante os anos de crise (1999-2002) no MS, a falta do crescimento econômico provocou uma queda dramática nas taxas de emprego e um aumento da pobreza e da exclusão social. Contudo, as taxas de crescimento econômico registradas no período posterior no Brasil, na Argentina e no Uruguai resultaram em melhorias em termos de rendimentos, bem como numa pequena redução dos níveis absolutos de pobreza.

Tabela 1 - Mercosul: indicadores sociais

\begin{tabular}{|l|l|l|l|l|l|l|l|}
\hline & Argentina & Brasil & Paraguai & Uruguai & Bolívia & Chile & Venezuela \\
\hline $\begin{array}{l}\text { População } \\
\text { (milhão) }\end{array}$ & 38.747 & 186.405 & 6.158 & 3.463 & 9.182 & 16.295 & 26.749 \\
\hline$\%$ Urbana & 90,6 & 84,2 & 58,3 & 93,0 & 64,4 & 87,7 & 88,1 \\
\hline $\begin{array}{l}\text { Expectativa de } \\
\text { vida }\end{array}$ & 74,9 & 71,3 & 71,5 & 75,9 & 64,9 & 78,3 & 73,4 \\
\hline$\%$ alfabetizada & 97,2 & 88,9 & 94,4 & 98,0 & 88,3 & 96,5 & 94,0 \\
\hline $\begin{array}{l}\text { Escolaridade } \\
\text { média (anos) }\end{array}$ & 8,8 & 4,9 & 6,2 & 7,6 & 5,6 & 7,5 & 6,6 \\
\hline $\begin{array}{l}\text { Pib/capita } \\
\text { (US } \$ \text { mil) }\end{array}$ & 11.410 & 7.510 & 4.690 & 7.980 & 2.490 & 9.810 & 4.750 \\
\hline $\begin{array}{l}\% \text { população } \\
\text { abaixo da linha } \\
\text { de pobreza }\end{array}$ & 3,3 & 8,2 & 16,4 & 2,0 & 14,4 & 2,0 & 14,3 \\
\hline \begin{tabular}{l} 
IDH \\
\hline
\end{tabular} & 0,863 & 0,792 & 0,755 & 0,840 & 0,687 & 0,854 & 0,772 \\
\hline
\end{tabular}

HUN IE: Urganızación Panamerıcana de la Salud, 2005 e World Bank. Elaboração do autor.

Nas últimas duas décadas, observa-se uma acentuação da desigualdade nos rendimentos, a qual tendeu a crescer junto ao crescimento da renda per capita e à redução das taxas de pobreza absoluta.

(5) De acordo com a pesquisa Radar Social do IPEA, 1\% dos brasileiros mais ricos — 1,7 milhão de pessoas— detém uma renda equivalente a da parcela formada pelos $50 \%$ mais pobres (86,5 milhões de pessoas). IPEA, junho de 2005 .

(6) Dados da ODM 15, 2006.

(7) Dados da empresa Equis - Equipos de Investigación Social.

(8) Dados do INDEC, 2003. 
Tabela 2 - Mercosul restrito: macrodados econômicos, US\$ milhões, preços constantes, 2005

\begin{tabular}{|c|c|c|c|c|c|}
\hline $\begin{array}{r}\text { Indicadores } \\
\end{array}$ & Argentina & Brasil & Paraguai & Uruguai & Total \\
\hline $\begin{array}{l}\text { Produto Interno Bruto } \\
\text { - } \quad \text { Participação (\%) }\end{array}$ & $\begin{array}{l}129.755 \\
20,31\end{array}$ & $\begin{array}{l}491.857 \\
77,00\end{array}$ & $\begin{array}{l}6.040 \\
0,94\end{array}$ & $\begin{array}{l}11.182 \\
1,75\end{array}$ & $\begin{array}{l}658.814 \\
100\end{array}$ \\
\hline $\begin{array}{l}\text { Valor Agregado Industrial } \\
\text { Participação (\%) }\end{array}$ & $\begin{array}{l}50.259 \\
26,46\end{array}$ & $\begin{array}{l}155.092 \\
71,15\end{array}$ & $\begin{array}{l}1.158 \\
0,67\end{array}$ & $\begin{array}{l}5.412 \\
1,78\end{array}$ & $\begin{array}{l}189.881 \\
100\end{array}$ \\
\hline $\begin{array}{l}\text { Formação Bruta do Capital Fixo } \\
\text { Participação (\%) }\end{array}$ & $\begin{array}{l}49.742 \\
24,07\end{array}$ & $\begin{array}{l}151.855 \\
73,47\end{array}$ & $\begin{array}{l}2.668 \\
1,29\end{array}$ & $\begin{array}{l}2.402 \\
1,16\end{array}$ & $\begin{array}{l}206.645 \\
100\end{array}$ \\
\hline $\begin{array}{l}\text { Exportações } \\
\text { Participação (\%) }\end{array}$ & $\begin{array}{l}37.564 \\
26,12\end{array}$ & $\begin{array}{l}99.006 \\
68,86\end{array}$ & $\begin{array}{l}5.007 \\
2,09\end{array}$ & $\begin{array}{l}4.199 \\
2,92\end{array}$ & $\begin{array}{l}145.776 \\
100\end{array}$ \\
\hline $\begin{array}{l}\text { Importações } \\
\text { - } \quad \text { Participação (\%) }\end{array}$ & $\begin{array}{l}27.155 \\
25,27\end{array}$ & $\begin{array}{l}75.078 \\
68,07\end{array}$ & $\begin{array}{l}5.554 \\
3,12\end{array}$ & $\begin{array}{l}5.778 \\
3,51\end{array}$ & $\begin{array}{l}107.545 \\
100\end{array}$ \\
\hline
\end{tabular}

FONTE: Elaboração do autor, a partir dos dados do Banco Mundial (Relatório 2005, World Economic Outlook, 2005) e da Cepal (Estadístico Anuário da América Latina e Caribe, 2005).

Pode-se observar nos dados acima a presença de grandes assimetrias entre os países do MS, as quais dificultam a efetividade dos direitos fundamentais na região. Da mesma forma, os persistentes desequilíbrios nas dimensões econômicas em termos de mercado, investimento e tecnologia se revelam como fortes obstáculos à integração em geral. As divergências evidenciam a necessidade de uma vontade política baseada nas concessões recíprocas e no interesse em promover e estender as oportunidades de melhoria de vida para as áreas mais pobres e menos competitivas. A experiência da União Europeia (UE) constitui-se numa prova de que a redução das disparidades econômicas regionais é uma condição necessária ao êxito da integração. Ela mostra que a expansão do comércio e a subscrição de acordos de cooperação são dois movimentos complementares.

Ficou evidente com as experiências de integração econômica em diferentes regiões do mundo que o caráter meramente comercial de certas formas de regionalização permite apenas uma cooperação relativamente limitada, sobretudo quando os parceiros possuem níveis desiguais de desenvolvimento econômico e social. Esses casos sugerem a aplicação de acordos voluntários e formais para aprofundar a integração e aumentar a sua eficiência. O êxito da integração exige esforços públicos que devem promover processos de convergência produtiva, institucional e social entre os comunitários.

Nesse sentido, destaca-se a iniciativa dos países do MS de estabelecer o Fundo de Convergência Estrutural, em dezembro de 2004, para abordar as necessidades infraestruturais e as assimetrias. O problema, no entanto, é que os recursos alocados estão muito aquém das carências. $\mathrm{O}$ Fundo recebe apenas 100 milhões de dólares por ano. O Brasil contribui com $70 \%$ do montante, a Argentina com 27\%, o Uruguai com 2\% e o Paraguai com $1 \%$. Em termos de distribuição, o Paraguai recebe $48 \%$ dos fundos, o Uruguai $32 \%$ e a Argentina e o Brasil, 10\% cada um. 
A falta de recursos internos para modernizar a infraestrutura econômica não está sendo compensada por investimentos estrangeiros no setor, como se esperava após o esgotamento do processo de substituição de importações e a abertura dos mercados. No contexto neoliberal das últimas décadas, a força da competição monopolista entre os capitais e países impulsiona a convergência dos benefícios sociais para um nível mínimo (próximo aos níveis dos países mais atrasados). O ajustamento "para cima", segundo o nível de proteção social dos países mais desenvolvidos, esbarra, ele, contra inúmeros obstáculos, como a escassez do emprego, a instabilidade dos negócios, a crise dos sistemas de seguridade social. Enquanto isso, a estratégia da "convergência por baixo" impede que as diferenças dos custos de mão de obra joguem a favor dos países e regiões menos desenvolvidas, de modo que os prometidos investimentos estrangeiros não chegam e, consequentemente, não há emprego e renda adicionais suficientes para reduzir o gap dos sistemas de proteção social.

Paradoxalmente, no mesmo contexto de generalização das leis de mercado, a agenda social, especificamente, exige uma intervenção maior dos poderes públicos. Em primeiro lugar, porque o tema do emprego exige um tratamento mais amplo que possa levar em consideração as realidades atuais dos mercados nacionais de trabalho, tão afetados pela precariedade, a baixa qualificação e as pressões de competitividade internacional. Em segundo lugar, porque a pobreza e a exclusão social persistem e contrariam o projeto neoliberal de aumentar a cobertura social privada da população em geral pela via do mercado. Finalmente, e não menos importante, devido ao fato de que a política social não opera apenas como sistema de proteção e estabilidade social, mas também o faz como fator produtivo, isto é, como alavanca do próprio crescimento econômico via sustentação da demanda e qualidade da mão de obra.

De fato, no contexto atual em que a acumulação do capital tende a abranger a totalidade do campo social, pode-se encontrar no progresso social proposições de modelos de desenvolvimento econômico que pudessem sustentar mais adequadamente os processos de acumulação do capital. Essa inversão da relação tradicional progresso econômico a progresso social é a base para o processo da constituição de uma "cidadania social". A própria necessidade de encontrar novas formas de valorização do capital amplia os conceitos intelectuais e estratégicos de processos sociais inclusivos. Nisto, setores como o da saúde e o da educação são particularmente reconhecidos como fortes indutores de desenvolvimento e como fatores de crescimento econômico e de avanço científico e tecnológico, sobretudo em razão de suas relações intersetoriais nas áreas de serviços, indústria, tecnologia e agricultura. O seu fortalecimento é imprescindível ao desenvolvimento social, em razão, fundamentalmente, das suas contribuições à formação e preservação do capital humano.

\section{O PROCESSO DE INTEGRAÇÃo SOCIAL NO MS}

Impulso importante à ampliação do entendimento e valorização da agenda social real do MS foi dado a partir dos meados da década de noventa, quando foram considerados alguns dos direitos fundamentais na agenda de discussões: o compromisso dos países 
parceiros em garantir os valores do Estado de direito e, mais amplamente, da democracia; o interesse expresso em zelar, também, pelos direitos humanos no quadro mais amplo de um modelo de desenvolvimento econômico regional pautado pela justiça e pela igualdade ${ }^{(9)}$.

Tal movimento se desenvolveu por meio de dois eixos principais. De um lado, ampliaram-se os conceitos intelectuais e estratégicos no tratamento dos temas sociais no contexto da integração. De outro, ocorreu um processo de fortalecimento institucional na esfera social do MS, por meio da criação de novas e diversificadas instituições especificamente dedicadas à dimensão social.

Principais marcos legais e institucionais relacionados à integração social no Mercosul:

1995 - Fórum Consultivo Econômico e Social (FCES);

1995 - SGT-10 - Assuntos Trabalhistas, Emprego e Seguridade Social;

1995 - Rede Mercocidades;

1996 - SGT-1 1 - Saúde;

1996 - Sistema de Informação em Educação;

1997 — Tratado Multilateral de Seguridade Social;

1997 - Observatório do Mercado de Trabalho;

1998 — Declaração Sócio-Laboral do MS;

1999 - Comissão Sócio-Laboral;

2000 - Carta Social do MS;

2000 - Proposição da elaboração da agenda social da integração;

2001 - Sistema Estatístico de Indicadores Sociais (SEIS);

2002 - Grupo ad hoc de Integração Fronteiriça;

2004 - Primeira Conferência Regional de Emprego;

2004 - Fundo de Convergência Estrutural;

2005 - Fundo Social Especial;

2005 - Programa "Somos Mercosul”;

2006 - Primeira Cúpula Social;

2006 - Primeiro Encontro Mercosul Social e Produtivo;

2007 - Primeiro Fórum Social.

Essas instâncias e outras estão montando os arcabouços institucionais da integração social e seus atos jurídicos devem ser transpostos ou incorporados nas respectivas

(9) Os principais instrumentos sobre a matéria são os Protocolos de Ushuaia e de Assunção, que tratam, respectivamente, da importância da manutenção das instituições democráticas e da promoção e proteção dos direitos humanos e das liberdades fundamentais. Eles preveem a suspensão do direito de um Estado-membro participar do processo de integração em caso de ruptura da ordem democrática ou da ocorrência de graves e sistemáticas violações de direitos humanos. 
legislações nacionais de cada país, segundo os procedimentos correspondentes. No entanto, até agora menos da metade das normas decididas no âmbito do MS está em vigor nos países parceiros, o que ilustra claramente as dificuldades de harmonizar a legislação. Alguns setores apresentam um nível especialmente baixo de transposição, como os da justiça e da saúde.

A Resolução n. 20/95 instruiu o subgrupo de trabalho SGT-10 (Assuntos Trabalhistas, Emprego e Seguridade Social) a elaborar propostas para harmonizar as legislações trabalhistas dos países do MS e aproximar as normas regulamentadoras de saúde e segurança e meio ambiente de trabalho. Dentro do SGT-10, tratados bilaterais de complementação mútua de políticas sociais foram celebrados entre Brasil e Argentina e acordos multilaterais foram realizados para integrar na agenda de discussões medidas comuns que visam a erradicar o trabalho infantil, facilitar a livre circulação de trabalhadores e incluir o tema do emprego como objetivo de integração social. No entanto, não se efetivou ainda a correspondente construção institucional, nem mesmo nos planos jurídico e legal, da definição de uma normativa laboral mínima comum.

$\mathrm{Na}$ área da Educação Básica, o tratamento integral dos objetivos estratégicos do Sistema Educativo Mercosul pretende dar prioridade ao fracasso escolar que afeta especialmente os primeiros anos de escolaridade. Os grupos vulneráveis aos quais se dará atenção educativa prioritária para garantir seu acesso à educação, permanência e promoção são os setores populacionais em situação de marginalidade social, cultural e econômica.

Foram fixadas as seguintes metas que definirão os projetos a serem executados por esta área:

- Melhoramento da qualidade da educação para todos, dando ênfase na aprendizagem e gestão participativa contextualizada. Esse processo está ligado à flexibilidade curricular e está vinculado à autonomia dos educadores;

- Incorporação de projetos e atividades relativos ao ensino das Línguas, da História e da Geografia do Mercosul;

- Constituição de uma rede de instituições que permita o intercâmbio de experiências e a criação de um banco de informação sobre educação inclusiva;

- Promoção do bilinguismo e do ensino da história regional comum;

- Consolidação de um sistema comum de compatibilização dos créditos, diplomas e níveis de escolaridade;

- Produção de materiais didáticos e experiências pedagógicas;

- Garantia da mobilidade dos estudantes.

No âmbito do ensino superior, a necessidade de espaço acadêmico regional, a melhoria de sua qualidade e a formação de recursos humanos constituem os elementos essenciais para estimular o processo de integração. A criação de um espaço comum regional para a educação superior tem um dos seus pilares no desenvolvimento de programas que irão

106 
envolver projetos e ações de gestão acadêmica e institucional, mobilidade estudantil, sistema de transferência de créditos e intercâmbio entre docentes e pesquisadores. A cooperação interinstitucional é, neste sentido, de fundamental importância para promover e estimular ações conjuntas de desenvolvimento de programas de graduação e pós-graduação, dentro de redes de trabalho que se comunicariam com os outros níveis educacionais.

O maior dinamismo dos educadores e a facilidade de comunicação colocam a educação como a área em que se realizam avanços concretos de integração social. Com a pressão da sociedade civil, o projeto neoliberal para a educação foi redefinido e impediu-se que as reformas educacionais executassem todas as recomendações que o Banco Mundial emitia na década de 1980. Os índices de alfabetização são geralmente elevados, acima de $90 \% \mathrm{em}$ todos os países com exceção do Brasil, onde o índice é de $89 \%$. Segundo os indicadores do ODM, o tempo de escolaridade se prolongou e a taxa líquida de inscrição no ensino primário no Brasil subiu de 86\% em 1990-91, para 93\% em 2004 (ODM 15, 2006).

Na área da saúde, um Sub-Grupo de Trabalho, o SGT-1 1-Saúde, foi criado em 1996 especificamente para harmonizar as legislações e coordenar as ações nas áreas de serviços, insumos e produtos de saúde, como também na área de vigilância sanitária e epidemiológica. Diversas comissões intergovernamentais foram constituídas em seguida, com a finalidade de cuidar de inúmeros assuntos, como: políticas de medicamentos, saúde sexual e reprodutiva, gestão de riscos e redução de vulnerabilidades, saúde ambiental e do trabalhador, controle do sarampo, cólera, dengue e febre amarela, sistema de informação e comunicação em saúde, banco de preços de medicamentos etc.

Todavia, os avanços mais significativos em direção a uma integração na área da saúde estão concentrados na harmonização das regras de vigilância sanitária para a circulação dos produtos, na regulamentação da vigilância epidemiológica e na formação de um sistema de informações em saúde. São ações comuns que se tornam importantes à medida que aumente a circulação das pessoas e dos bens e serviços.

A partir do momento em que existe o livre trânsito das pessoas que podem migrar indistintamente de um país para outro, se coloca necessariamente a questão de saber que país será responsável pela seguridade social das populações migrantes. Essa responsabilidade será avaliada por meio da comparação entre os direitos e benefícios dos países de origem com os dos países hospedeiros. Se as prestações de seguridade social em geral são distintas, então de que sistema poderia se beneficiar o migrante?

Até o momento os direitos sociais dos cidadãos do MS se limitam aos territórios nacionais e não podem ser usufruídos nos países vizinhos, embora cidadãos paraguaios, uruguaios e bolivianos das áreas fronteiriças buscassem atendimento em saúde no Brasil, por meio do sistema público gratuito deste país. Municípios brasileiros arcam com o atendimento da demanda da população vizinha sem receber recursos financeiros e humanos adicionais.

A realidade das fronteiras traz determinações complexas no que se refere ao acesso à saúde na região, uma vez que os sistemas nacionais de saúde são diferenciados em termos de universalidade, equidade, modelos de cobertura e atenção, modalidades de oferta e financiamento. Enquanto o Brasil conta com o descentralizado e público Sistema Único de 
Saúde (SUS), os demais parceiros do MS possuem sistemas mistos público-privados, centralizados e com baixos e variados graus de cobertura.

As zonas de fronteira são espaços privilegiados e obrigatórios para iniciar o processo de integração e harmonização e, até mesmo, de unificação dos sistemas de seguridade social. Permitem observar os dilemas concretos do atendimento, avaliar localmente o uso formal e informal dos serviços sociais, conhecer a demanda real e as condições de acesso, assim como as possibilidades de construir estratégias cotidianas de cooperação e complementação.

\section{OS DESAFIOS DA INTEGRAÇÃO SOCIAL NO MS}

Teoricamente, o desafio à integração social no MS se inscreve no marco dos direitos fundamentais do homem e, portanto, leva em consideração os princípios de equidade, universalidade, participação, e descentralização. Abrange os direitos à educação, saúde, segurança, moradia, assistência e seguridade social. Cada um desses direitos requer intervenção pública em várias frentes de ação. $\mathrm{O}$ direito à saúde, por exemplo, somente pode ser garantido pela atuação conjunta de medidas de promoção, prevenção, recuperação e reabilitação. O direito à educação, especificamente, envolve não menos do que a possibilidade de ingresso em todos os níveis de ensino, a permanência da criança e do adolescente na escola, o acesso ao conhecimento e à formação profissional.

Em todos os direitos, para que a integração social se situe na perspectiva de elevar o nível de bem-estar das populações, a participação da sociedade civil é fundamental. A formação de uma verdadeira cidadania social supranacional, fundada em direitos sociais mínimos comuns, passa necessariamente por um processo inclusivo das políticas comuns, em conteúdos, formas e quadros institucionais. Entretanto, não se pode supor que a unificação apenas em forma e quadro institucional das políticas sociais seja suficiente para garantir benefícios sociais mínimos em sociedades em que poucos têm saneamento básico, moradia decente, plano de saúde e acesso à educação de qualidade.

Na tabela abaixo, pode-se observar uma relação negativa e lamentável entre a pobreza e o percentual da renda gasta em saúde, assim como uma relação positiva entre essas duas variáveis e as condições de saúde (expectativa de vida e taxa de mortalidade infanto-juvenil). Ela mostra, também, a disparidade que existe nestes indicadores entre os países do MS e alguns países da Europa. 
Tabela 3 - Indicadores Selecionados, 2005

\begin{tabular}{|c|c|c|c|c|}
\hline Indicadores & $\begin{array}{c}\text { Pib per } \\
\text { capita } \\
\text { US\$ }\end{array}$ & $\begin{array}{c}\text { Gasto em saúde } \\
\% \text { do Pib }\end{array}$ & $\begin{array}{c}\text { Expectativa de vida ao } \\
\text { nascimento (média: } \\
\text { Homem-mulher) }\end{array}$ & $\begin{array}{c}\text { Mortalidade } \\
\text { infanto-juvenil } \\
\text { (por mil) } \\
\end{array}$ \\
\hline Argentina & 15.920 & $\begin{array}{c}9,6 \\
(2004)\end{array}$ & $74,9^{+}$ & 16 \\
\hline Brasil & 8.250 & $\begin{array}{c}8,8 \\
(2004)\end{array}$ & 71 & $\begin{array}{c}55 \\
(2004)\end{array}$ \\
\hline Bolívia & 2.740 & $\begin{array}{c}6,8 \\
(2002)\end{array}$ & $65^{+}$ & $\begin{array}{c}65 \\
(2004)\end{array}$ \\
\hline Chile & 11.470 & $\begin{array}{c}6,1 \\
(2004)\end{array}$ & 78 & 10 \\
\hline Espanha & 25.820 & 8,1 & 80 & 5 \\
\hline Etiópia & 1.000 & 5,5 & 52 & 164 \\
\hline França & so. 540 & 10,5 & 82 & 5 \\
\hline Hungria & 16.940 & 7,9 & 75 & 8 \\
\hline Irlanda & 54.720 & 7,2 & 79 & 5 \\
\hline Paraguai & 4.970 & $\begin{array}{c}7,7 \\
(2004) \\
\end{array}$ & $71^{+}$ & 25 \\
\hline Uruguai & 9.810 & $\begin{array}{c}8,2 \\
(2004) \\
\end{array}$ & 75 & 15 \\
\hline Venezuela & 6.440 & $\begin{array}{c}4,7 \\
(2004)\end{array}$ & 75 & 21 \\
\hline
\end{tabular}

FONTE: OMS, World Health Statistics, 2007.

* Organización Panamericana de la Salud, 2007; World Bank, 2005. Elaboração do autor.

Quanto mais distintos forem os indicadores sociais dos países associados maior será a dificuldade de harmonizar os sistemas e serviços de atendimento. No setor de saúde, observa-se uma marcada diferença nos indicadores entre os países sócios ${ }^{(10)}$, tanto no que diz respeito às doenças e às taxas de mortalidade, como no que se refere aos recursos alocados.

Tabela 4- Mercosul: indicadores de mortalidade e de recursos alocados à Saúde

\begin{tabular}{|l|c|c|c|c|c|c|c|}
\hline & Argentina & Brasil & Paraguai & Uruguai & Bolívia & Chile & Venezuela \\
\hline Mortalidade infantil por mi & $\begin{array}{c}16,5 \\
(2005)\end{array}$ & $\begin{array}{c}55,0 \\
(2005)\end{array}$ & $\begin{array}{c}25,0 \\
(2005)\end{array}$ & $\begin{array}{c}15,0 \\
(2005)\end{array}$ & $\begin{array}{c}65,2 \\
(2004)\end{array}$ & $\begin{array}{c}10,0 \\
(2005)\end{array}$ & $\begin{array}{c}21,2 \\
(2004)\end{array}$ \\
\hline Mortalidade materna por & 45,6 & 75,1 & 174,1 & 25 & 250 & 15,4 & 57,8 \\
100 mil & $(2005)$ & $(2002)$ & $(2005)$ & $(2002)$ & $(99-05)$ & $(2005)$ & $(2005)$ \\
\hline Gastos públicos (\% PIB) & 5,0 & 5,6 & 2,9 & 2,0 & 4,5 & 2,9 & 1,4 \\
\hline Gastos privados (\% PIB) & 5,9 & 5,6 & 4,1 & 10,4 & 2,9 & 5,8 & 2,7 \\
\hline
\end{tabular}

FONTE: OPS Health Situation in Americas. Basic Indicators, 2005 e OMS, 2007.

(10) Indicadores nacionais que ocultam as diferenças regionais internas. 
Bouzid Izerrougene - Cadernos PROLAM/USP ( Ano 7 - Vol. 2 - 2008) p. 100-112

Tabela 5 - Médicos por 10 mil habitantes (2001)

\begin{tabular}{|c|c|c|c|c|c|c|}
\hline Argentina & Brasil & Paraguai & Uruguai & Bolívia & Chile & Venezuela \\
\hline 52,1 & 20,6 & 5,6 & 39,0 & 7,6 & 11,5 & 20,0 \\
\hline
\end{tabular}

FONTE: OPS Health Situation in Americas. Basic Indicators, 2005.

A mortalidade infantil no Brasil registra uma taxa duas vezes maior do que a do Uruguai e Argentina. A mortalidade materna do Paraguai é de 174 por cem mil, enquanto a do Uruguai é de 23. A população sem acesso a água potável varia também bastante, desde $2 \%$ no Uruguai a 17\% no Paraguai em 2005 (comparado, no entanto, com 38\% em 1990). Em 2003, a taxa de mortalidade de crianças com menos de cinco anos ficou entre 17/1000 (Uruguai) e 34/1000 (Brasil) ${ }^{(11)}$. Estes e outros dados ilustram as diferenças existentes entre os quatro países.

As divergências se acentuam nos sistemas de saúde que vigoram em cada país, assim como nos seus respectivos padrões de financiamento. O sistema brasileiro é de natureza pública, financiado por impostos e contribuições que remuneram ações e serviços de saúde nos níveis públicos e privados e pagam os medicamentos básicos e emergenciais. Os demais sistemas nacionais se organizam essencialmente em seguros privados, e as ações do setor público são muito limitadas. Os valores mais reduzidos de cobertura em toda a América Latina se encontram nos parceiros do Brasil no MS: Bolívia (35\%), Paraguai (46\%), Argentina (48\%) e Uruguai $(53 \%)^{(12)}$.

Quando as fronteiras se ampliam e os fluxos migratórios se expandem, os antigos sistemas nacionais podem passar à categoria de subsistemas de um sistema supranacional maior e mais complexo, e as relações que se estabelecem entre os sistemas sociais implicam num maior planejamento e maiores competências de gestão. No mesmo tempo, a capacidade profissional de atender à nova realidade, tanto para administrar o sistema, como para assegurar um atendimento social mínimo, tropeça contra a escassez dos recursos humanos e a sua concentração nas zonas urbanas e nas áreas de maior desenvolvimento econômico. A unificação das políticas sociais sofre então muitas dificuldades, como a precariedade do trabalho, a fuga dos recursos humanos para as regiões mais ricas, o deslocamento dos usuários e a consequente desigualdade no acesso aos direitos. Isso mostra como as desigualdades socioeconômicas e sanitárias têm forte expressão territorial e evidencia a importância de políticas regionais de intervenção pública.

O exemplo da construção da UE revela que o processo de unificação social é muito mais complexo do que o processo de unificação nos âmbitos das políticas econômicas, comerciais e financeiras. Os avanços de integração social que se realizaram na Europa só foram possíveis na área da seguridade social depois que se abriu mão da estratégia de convergência pelo alto; quando a ideia de um modelo unificado de proteção foi substituída por políticas pontuais de reconhecimento e compensação de direitos nacionais, de equivalências e de transferências orçamentárias. Na UE os Estados-membros são praticamente os únicos responsáveis por suas políticas sociais.

(11) ODM, idem.

(12) Dados da CEPAL — Serie Políticas Sociales, 2005

110 


\section{Considerações finais}

Em seus discursos, os líderes comunitários não cansam de reafirmar a necessidade de se dar corpo ao Programa de Fortalecimento do Mercosul Social, por meio de políticas econômicas e sociais inclusivas, voltadas para a redução da pobreza e da desigualdade na região. Segundo os últimos dados consolidados, entre 1990 e 2003, quase todos os países do MS registraram progressos em diversos domínios sociais. Todavia, mesmo reconhecendo nos fatos algum avanço, não se pode perder de vista que os indicadores são calculados a partir de uma base reduzida de comparação, e que os resultados absolutos são notoriamente modestos e muito aquém das necessidades.

Os déficits sociais se associam às condições econômicas e culturais e à má distribuição de renda. Outras dificuldades se devem a fatores sociodemográficos que caracterizam a região, como a alta dispersão geográfica nas zonas rurais, que se traduz, diante da precariedade dos meios de transporte, pela inacessibilidade aos serviços de saúde e educação. Para além da falta de recursos e das divergências econômicas e administrativas, incidem também sobre os processos de integração os conflitos políticos e de interesses, as idiossincrasias nacionais, a força de inércia que em geral caracteriza as relações institucionais e a inexperiência dos negociadores. Enquanto isso, a maior fonte de pobreza, o desemprego estrutural, afeta crescentes contingentes de trabalhadores nos setores industriais e de agricultura familiar e alimenta a exclusão social ${ }^{(13)}$.

Os desafios para a integração social são grandes e, a este respeito, o MS não é único a se confrontar com obstáculos, como provam as dificuldades da União Europeia. Nesta, as limitações das políticas sociais parecem quase infranqueáveis. Palavras como unificação e convergência social desapareceram do discurso oficial. Não têm mais lugar no projeto minimalista de harmonização das políticas nacionais.

As dificuldades europeias de integração social derivam, em grande proporção, da existência na maioria dos países de sistemas de proteção sociais que são profundamente enraizados em fortes tradições culturais e históricas. No MS a situação é, todavia, diferente, devido à semelhança dos baixos índices de proteção social, cuja solução pode ser mais facilmente encontrada via ações e estratégias comuns.

\section{REFERÊNCIAS BIBILOGRÁFICAS}

CEPAL. Serie Políticas Sociales. 2005. - Panorama Social da América Latina. 2004.

DRAIBE, Sônia Miriam. Coesão social e integração regional: a agenda social do Mercosul e os grandes desafios. Disponível em: <http://www.scielo.br/pdf/csp/v23s2/06.pdf> Acesso em: 14.2.2008.

EQUIS. Equipos de Investigación Social. Disponível em: <http://www.geocities.com/CapitolHill/ 3439/> Acesso em: 14.3.2008.

(13) $15 \%$ é a taxa média de desemprego no MS, segundo os organismos oficiais de cada país. 
FUNDAÇÃO OSWALDO CRUZ. Disponível em: < http://www.fiocruz.br/cgi/cgilua.exe/sys/ start.htm?tpl=home > Acesso em: 23.3.2008.

HOLANDA, Enir Guerra Macedo. A saúde no Mercosul e integração regional. Disponível em: <http:// www.ensp.fiocruz.br/parcerias/redsalud> Acesso em: 24.2.2008.

IDEC. Instituto Brasileiro de Defesa do Consumidor. Disponível em: < http://www.saude.sc.gov.br/ cidadao/cartilha_SUS.doc> Acesso em: 14.2.2008.

. Instituto Nacional de Estadística y Censos. Buenos Aires, 2003. Disponível em: <http:// www.indec.mecon.gov.ar/> Acesso em: 21.6.2008.

LUCCHESE, Geraldo. Políticas sociais integradas. Questões estratégicas da integração regional para as políticas e sistemas de saúde no Mercosul. Disponível em: <http://www.ensp.fiocruz.br/parcerias/redsalud> Acesso em: 24.2.2008.

GALO, Edmundo; COSTA, L. (orgs.). Sistema integrado de saúde do Mercosul: SIS — Mercosul uma agenda para integração. Ministério da Saúde Brasil. Organização Pan-Americana da Saúde, 2004.

ODM 15. Objectivos de Desenvolvimento do Milénio, 2006. Disponível em: <http://www. objectivo2015.org/odm/present/obj1present.shtml> Acesso em: 29.3.2008.

OMS. Organização Mundial de Saúde. Disponível em: <http://www.who.int/countries/chl/fr/> Acesso em: 26.3.2008.

ORGANIZACIÓN PANAMERICANA DE LA SALUD. Disponível em: < http://www.paho.org/ spanish/dd/ais/coredata.htm> Acesso em: 15.3.2008.

PAOLO, L. J. Di Pietro. La dimensión social del Mercosur: recorrido institucional y perspectivas. Disponível em: <http://www.iadb.org/intal/> Acesso em: 16.12.2007.

SISTEMAS DE INFORMAÇÃO EM SAÚDE DO MERCOSUL. Disponível em: <http:// www.mercosulsalud.org/portugues/sgt/rosgt11/index.htm> Acesso em: 24.3.2008.

UNDP. Human Development Report. 2006.

Human Development Report. 2007/2008.

WORLD BANK. Relatório Anual. 2005. 